\title{
Caminhos da dramaturgia latino-americana
}

\author{
Ana Maria Rebouças
}

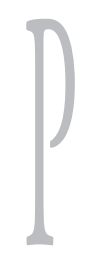

rocessos de criação dramatúrgica envolvendo constantes feedbacks entre texto e cena são característicos da produção brasileira atual, e provavelmente estejam sendo praticados um pouco por toda parte do mundo, com diferentes resultados. Refletindo sobre a dramaturgia contemporânea na Argentina, Jorge Dubatti considera que há um "fenômeno de multiplicação do conceito de escritura teatral (...) que permite reconhecer diferentes tipos de dramaturgias e textos dramáticos: entre outras distinçôes, a dramaturgia de autor, de diretor, de ator e de grupo, com suas respectivas combinações e formas híbridas, as três últimas englobáveis no conceito de dramaturgia de cena” (Dubatti, 2003, p. 6). Uma geração de autores argentinos, como mostra Dubatti, tem produzido textos teatrais que lidam com novos paradigmas formais que resultam teatralmente expressivos em cena, mas também literariamente elaborados.

Segundo Sílvia Fernandes, "o resultado da apropriação da teatralidade pela dramaturgia mais recente é que o texto literário ganhou novo estatuto. O dramático ainda se conserva no modo de enunciação, na construção dos diálogos, monólogos ou narrativas e, algumas vezes, no desdobramento dos personagens. Mas a qualidade teatral deixa de ser medida pela capacidade de criar ação. Agora teatral pode ser apenas espacial, visual, expressivo no sentido da projeção de uma cena espetacular" (Fernandes, 2001, p. 70).

Com o tema Caminhos Abertos, a edição de 2004 do Festival Internacional de Londrina apresentou, além de montagens que envolvem formas híbridas de linguagem, uma gama de espetáculos latino-americanos concebidos a partir de processos dramatúrgicos diversos. Yocasta, da dramaturga e atriz uruguaia Mariana Percovich, Calendário da Pedra, de Denise Stoklos e Café Com Queijo, do Grupo Lume, proporcionam uma visão da dramaturgia escrita pelo ator, seja em um projeto solo ou em equipe. Outros grupos apresentados, como a Cia. do Feijão e o Ateliê de Criação Teatral dirigido por Luís Mello, mostram expressões de uma dramaturgia concebida a partir da colaboração entre dramaturgo, diretor e atores, utilizando jogos e improvisaçôes. Entretanto, dentro da diversidade da programação do FILO, a dramaturgia de autores-diretores latino-americanos se destaca pelo caráter inovador dos textos apresentados, como é o caso de Tus deseos en fragmentos, de Ramón Griffero, Mosca, escrito por Fábio Rubiano a

Ana Maria Rebouças é pesquisadora do Centro Cultural São Paulo, mestre em Artes Cênicas pela ECA-USP. 
partir de Tito Andrônico, de Shakespeare e de dois textos argentinos: La Bohemia, de Sérgio Boris e La forma que se despliega, de Daniel Veronese. Neste artigo pretendo apontar algumas características destes textos, acentuando a relação que estabelecem com a cena. Todos foram escritos previamente ao processo de criação do espetáculo, e depois passaram por uma segunda fase de re-escritura cênica junto com os atores.

\section{Tus deseos en fragmentos}

Em 1984, Ramón Griffero funda, em Santiago do Chile, o grupo de teatro Fin de Siglo e o espaço de resistência cultural El Trolley, que se transforma em sede de um movimento artístico de música, artes plásticas, vídeo, dança, poesia etc., e onde Griffero dirige várias performances e açôes artísticas, tendo, além disso, lá apresentado seus primeiros trabalhos como diretor e dramaturgo. Desde então, vem desenvolvendo uma pesquisa que procura a autonomia da linguagem teatral, a partir da teorização e da prática de uma "dramaturgia do espaço", resultante da conexão de uma poética da imagem com uma poética do texto que se projetam na cena.

A peça Tus deseos en fragmentos (Seus desejos em fragmentos) propõe um tour pelo "museu interno" do personagem Tu em seus últimos momentos de vida. O texto é segmentado em fragmentos que delimitam as salas desse museu, cada qual apresentando uma temática predominante: desejo, medo, amor, morte, etc. Os personagens que transitam por essas salas são designados por pronomes: Ele, Ela, Uma, Aquele, e intercalam rápidos diálogos com monólogos que misturam ação e narração. Conforme eles entram e saem das salas, vão tecendo ramificações discursivas (temas recorrentes) que são retomadas por outros personagens em outras salas, traçando um mapa da atividade cerebral do personagem $\mathrm{Tu}$, que não segue a lógica da sucessão temporal linear e causal, mas sim a da analogia e das associaçóes.
De acordo com as indicações cênicas sugeridas por Griffero, "esses textos estão escritos para múltiplas instalações que se armam e desvanecem, produzindo uma sensação de labirinto mental, onde idéias, sonhos, desejos se intertextualizam com um mundo de imagens plásticas e conceituais". A progressão temporal da representação deriva dessa concepção rizomática do espaço. A conexão entre um fragmento e outro (ou entre uma sala e outra) deve, ainda conforme as indicaçōes do autor, seguir o princípio da simultaneidade. Daí os textos se interconectarem em uma leitura espacial, gerando ritmos que se instauram na dinâmica do cenário. Isso confere inúmeras possibilidades de montagem ao encenador cujo trabalho, para Griffero, se assemelha ao de um arqueólogo que escava idéias (conceitos) para desenterrar templos e cidades.

Conhecendo as coordenadas espaço temporais propostas pela "dramaturgia do espaço" concebida por Griffero, podemos perceber que, em última instância, a peça propõe uma unidade de tempo e de espaço ficcionais que se abre em vários planos. Apesar de compreender várias salas, o espaço que as contém é o cérebro humano, imaginado metaforicamente como "museu interno". É na montagem e na justaposição dessas salas que podemos perceber a incorporação do código cinematográfico. Como se estivéssemos na frente de uma tela de cinema, as cenas vão se desdobrando, ocupando o palco de forma aparentemente aleatória, desenhando mutações no ambiente, sem seguir uma linearidade narrativa. Os praticáveis, as luzes, as projeções, segmentam o espaço em geometrias que são traçadas nos diferentes planos possíveis dentro do retângulo da caixa preta do palco.

Sobre os personagens, Griffero indica: "são falantes; cada corpo assume diversas vozes... há vozes que voltam a emergir de um corpo esquecido, há outras que são memórias de outras que falam por seu corpo; há vozes que são registros/gravaçôes. Há personagens a desentranhar que contêm outros. Há falantes no presente do passado e outros do desejo". Também aqui os 
personagens se subordinam às operações analógicas da mente humana, que tende a elaborar sínteses e associaçōes entre pessoas do passado e do presente, entre rostos familiares e desconhecidos, entre situações vividas e imaginadas.

$\mathrm{O}$ artigo de Sílvia Fernandes ajuda a esclarecer algumas questôes sobre a dramaturgia de Griffero. Ao traçar um resumo da evolução dos estudos sobre a escrita teatral, assinala que Patrice Pavis fala de "personagens como meras funções de enunciação e não mais como sujeitos com autonomia ficcional suficiente para lhes permitir ser agentes de um conflito dramático”. Cita ainda Stephen Watt, que considera a "subjetividade migratória como característica básica do drama mais recente, em que a identidade humana é marcada em termos de horizontalidade, e liga-se a travessias territoriais e ocupações temporárias de espaço, constituindo-se em termos bastante diferentes daqueles que enformam os modelos tradicionais de construção de personagem, mais próximos do aprofundamento vertical" (Fernandes, 2001, p. 70).

$\mathrm{O}$ texto de Griffero parece demonstrar essas considerações. Os personagens se relacionam de forma promíscua: seus desejos se cruzam, suas vozes se fundem, seus corpos assumem diferentes papéis, como se fossem projeções do personagem Tu. Numa primeira leitura, a peça pode parecer ter como tema os encontros e desencontros amorosos entre casais hetero e homossexuais, a partir dos amantes que habitam a memória de Tu. No entanto, em meio a esses fragmentos de diálogos e monólogos de vozes que se procuram e se amam, se agridem, se perdem e se anulam, há vários intertextos (a história do Chile, a infância destruída, a condi- ção da juventude latino-americana no mundo globalizado) que nos dão idéias dos caminhos que o personagem $\mathrm{Tu}$ percorre (por discursos provindos de lugares, pessoas e épocas diferentes) para compreender a rede de relações em que submerge sua vida. Num entendimento intrasubjetivo da identidade humana, todos esses discursos e vozes que habitam sua memória pessoal e histórica o constituem enquanto personagem que está deixando de existir. Neste momento, Tu encontra-se com personagens portadores de discursos que formam sua subjetividade, e se dissolve neles.

Tus deseos en fragmentos é uma obra caleidoscópica, que se abre para múltiplas perspectivas de interpretação. Mas é também uma peça que fala da América Latina e especialmente do Chile e de sua juventude. Remete a traços característicos do latino-americano na forma com que discursa sobre a morte, nos toques de humor negro, no comportamento sexual dos amantes, nos diálogos amorosos que roçam ou troçam do melodrama e na forma com que se refere, por exemplo, à Cordilheira dos Andes, como podemos verificar pelos trechos a seguir.

\section{El salón del aparte}

UNA: Espero que se acerque sentir su aliento. Lo espero ahí viene.

TU: Me acerco, pero tocaré su pierna para sorprenderla, para ver sí esta ahí.

UNA: Le acaricio su pelo. Aprieto su cráneo... TU: Me revuelve los cabellos. Y así me quedaría dormido... Cada uno pensando en el otro... en lo que estamos.

1 O salão do aparte. UMA: Espero que se aproxime sentir seu vigor. O espero aí vem. TU: Me aproximo, mas tocarei sua perna para surpreendê-la, para ver se está aí. UMA: Acaricio seu cabelo. Aperto seu crânio. TU: Me revolve os cabelos. E assim ficaria dormindo... Cada um pensando no outro... com quem estamos. UMA: E minhas pálpebras se fecham, para vê-lo por dentro... TU: Respondo. Abro os olhos e sorrio. UMA: Vejo que sorri e meus lábios se abrem, se estiram aparecem meus dentes. TU: Rimos. Do que? UMA: Aparece seu rosto sorrindo. TU: Ela vê meu sorriso, vê que estou... vai esticar seus braços. UMA: Estico meus braços, o envolvo... Meus olhos voltam a se fechar. Encontro-me com 
UNA: Y se me cierran los párpados, para verlo por dentro...

TU: Le respondo. Abro los ojos y sonrío.

UNA: Veo que sonríe y mis labios se abren, se estiran aparecen mis dientes.

TU: Nos reímos..¿De que?

UNA: Aparece su cara riendo.

TU: Ella ve mi sonrisa, ve que estoy... va estirar sus brazos.

UNA: Estiro mis brazos, lo envuelvo... Se vuelven a cerrar mis ojos... Me encuentro con su olor, lo aspiro.

TU: Escondo su cabeza en mi cuello y miro lo que nos rodea.

UNA: Estoy tan bien que me da miedo.

TU: No puedo decirle estoy enfermo, no le diré, me alejaré, haciendo que todo se disuelva como todo.

UNA: Necesito sus labios la humedad de su boca.

TU: Ya es tarde no lo dije en un comienzo, no lo puedo decir ahora.

UNA: Ahora sé por que morir.

TU: Sé que sabe que la amo sé que un día sabrá por que la dejo.

\section{El salón del suicidio (trecho) ${ }^{2}$}

ELLA: No se podía vivir al lado de la cordillera ... era todo de mentira..y la mentira no me dejaba respirar... Era de noche y todo seguía alumbrado... era verano. Ellas con sus bikinis en las playas, ellos tostados jugando con las paletas... Tomé el tren que iba por orillas del mar... mirando los rieles por donde caminamos... donde fuimos felices recostados sobre las dunas... Ellos comían helados y inflaban sus pelotas de colores... por la ventana... miradores alambres de puas... presos alineados y ellos seguían echándose bronceador... como crees que podría vivir en ese país... Ahí en la calle Valparaíso decidí comprar la cuerda...

\section{Mosca}

O ator, diretor e dramaturgo colombiano, Fábio Rubiano, formou em 1985 o Teatro Petra, um coletivo criativo que se reúne por períodos definidos de tempo, quando há um projeto a desenvolver. As principais propostas do grupo são as de encenar textos de dramaturgos latinoamericanos contemporâneos (entre ele os do próprio Rubiano) e criar uma dramaturgia própria a partir de obras clássicas. Para Rubiano, as atividades de escrita e direção estão muito vinculadas. Na criação do espetáculo Mosca, por exemplo, cerca de 80 por cento do texto estavam escritos quando os atores começaram a ensaiar. Cada um deles teve autonomia para criar a interpretação, o figurino e a trilha sonora. Com relação a esta última, os atores pesquisaram um tema musical para seus personagens e,

seu cheiro, o aspiro. TU: Escondo sua cabeça em meu colo e olho o que nos rodeia. UMA: Estou tão bem que me dá medo. TU: Não posso lhe dizer que estou doente, não o direi, me afastarei fazendo com que tudo se dissolva como tudo. UMA: Preciso de seus lábios a umidade de sua boca. TU: Já é tarde não lhe disse no começo, não posso dizer agora. UMA: Agora sei por que morrer. TU: Sei que sabe que a amo sei que um dia saberá por que a deixo. (Tradução da autora).

2 O salão do suicídio. ELA: Não se podia viver ao lado da cordilheira... era tudo de mentira e a mentira não me deixava respirar. Era de noite e tudo continuava aceso... era verão. Elas com seus biquínis nas praias, eles tostados jogando com as raquetes. Tomei o trem que ia pelas margens do mar... olhando os trilhos por onde caminhamos... onde fomos felizes recostados sobre as dunas... Eles tomavam sorvete de bolas coloridas... pela janela... mirantes de arames farpados... presos alinhados e eles continuavam passando bronzeador... como crê que eu poderia viver nesse país... aí na rua Valparaíso decidi comprar a corda... (Tradução da autora). 
em alguns momentos, ligavam um gravador portátil com a música selecionada. O processo do grupo se caracteriza pela incorporação de uma dramaturgia pessoal, alcançada a partir da investigação e das contínuas descobertas que vêm da diversidade de seus integrantes e das suas experiências com outras companhias. Essa característica resultou em achados cênicos surpreendentes e originais, como tentarei demonstrar a partir de alguns exemplos que apontam para a relação entre texto e cena.

Toda a peça se passa ao redor de três mesas de madeira rústica dispostas ao longo de uma área retangular, formando um largo corredor. Nas extremidades, duas portas funcionam como entrada e saída dos atores. Nas laterais, duas arquibancadas se estendem ao longo do cenário, para um público de mais ou menos 150 pessoas, que fica muito próximo dos atores. $\mathrm{O}$ general Tito entra, usando meia-calça preta de tecido grosso, sandálias de salto alto, um manto preso por um broche brilhante e adornado com insígnias militares, portando uma coroa de louros. Em alguns momentos de sua fala, esquarteja legumes - pepinos, pimentóes, cebolas - que estão sobre a mesa, e os coloca em uma travessa.

Tito: ¿Por cuántas cosas tiene que pasar un hombre antes de poder descansar?

Resumen:

10 años: De guerra.

30 años: De concúbitos.

26 hijos: Legítimos.

(Pausa)
22 muertos a manos de los godos.

Voy y vuelvo de la guerra por lo menos en 5 ocasiones durante 10 años.

Como soy un guerrerocomandantevalientesoldadodirectordetropasyvencedor: Las mujeres... todas... Es difícil.

Te miro y ya te imagino favoreciéndome: $\mathrm{Ne}$ gras, mulatas, blancas, indias, sin color, sin edade.

(...)

26 hijos varones y una mujer.

22 hijos varones muertos a manos de los godos. (Rompe a llorar. Abre un maletín donde reposan los restos de sus 22 muertos)

Estos son los cadáveres de mis 22 hijos muertos a manos de los godos.

No lloro por ellos.

(Deja de llorar)

Lhego de la guerra y quierem que sea Rey.

¡No!, digo.

Estoy cansado estoy viejo quiero enterrar a mis hijos tengo nudos en la espalda y una rodilla me repercute.

Pero insisten.

Tres guerras, tres tres três. ${ }^{3}$

Tito segue fazendo o resumo da sua vida e da situação do Reino após a guerra contra os godos, que têm como chefe uma mulher, Tamora. Em seguida, como desagravo pela morte de um de seus 22 filhos, mata um filho de Tamora e declara que então podem firmar uma trégua. A partir daí todos se reúnem em torno da mesa para negociar a paz, mas por baixo dela armam-se ciladas.

3 TiTo: Por quantas coisas tem que passar um homem antes de poder descansar? Resumo: 10 anos: De guerra. 30 anos: De concubinatos. 26 filhos: Legítimos. (Pausa). 22 mortos pelas mãos dos godos. Vou e volto da guerra pelo menos em 5 ocasiōes durante 10 anos. Como sou um guerreirocomandantevalentesoldadodiretordetropasevencedor: As mulheres... todas... É difícil. Te olho e já te imagino favorecendo-me: Negras, mulatas, brancas, índias, sem cor, sem idade. (...). 26 filhos varões e uma mulher. 22 filhos varōes mortos pelas mãos dos godos. (Irrompe a chorar. Abre uma maleta onde repousam os restos de seus 22 mortos). Estes são os cadáveres de meus 22 filhos mortos pelas mãos dos godos. Não choro por eles. (Deixa de chorar). Chego da guerra e querem que eu seja Rei. Não!, digo. Estou cansado estou velho quero enterrar meus filhos tenho nódulos nas costas e um joelho me repercute. Mas insistem. Três guerras, três três três. (Tradução da autora). 
$\mathrm{O}$ que chama a atenção na peça escrita e dirigida por Rubiano a partir de Tito Andrônico, de Shakespeare, é o efeito obtido por meio de um mecanismo que, acionado, faz com que a violência se repita numa escalada crescente, resultando na sua banalização. A partir disso, o discurso da paz só pode ser tomado como retórica esvaziada de sentido. $\mathrm{O}$ registro de farsa adotado por Rubiano não poderia resultar mais apropriado. Harold Bloom, que considera esta uma das piores obras de Shakespeare, toma-a como um aprendizado, quando o bardo ainda tentava exorcizar as influências de Marlowe, levando-as ao extremo do mau-gosto. Bloom afirma que só poderia conceber uma montagem de Tito ... como farsa. Mas o fato é que, na recriação do Teatro Petra, essa farsa macabra e perversa é levada ao paroxismo, ganhando radical contundência e atualidade. Todos os sentimentos, que no original poderiam ser tomados como ternos, e todas as intenções de promover a paz, são representados pelos atores de Mosca com a máscara da hipocrisia. Num ambiente em que impera o simulacro, as negociações têm o único objetivo de iludir o inimigo com promessas de acordo, para em seguida fazê-lo cair em armadilhas.

Tamora lleva un pequeño peinado afro. Se queda en la puerta, abre los brazos, da una vuelta sobre su propio eje, se muestra.

Tamora: Completamente desprovista de alfanjes, estiletes o espadas.
TiTo: (Sonriente) Veo a una Tamora desarmada y creo no conocerla.

Tamora: (Sonriente) Veo al gran TiTo y lo reconozco por ser el mismo que ordenó a Bassiano descuartizar a mi hijo Alarbo y alimentó com sus entrañas el fuego del sacrificio...

TiTo: Que buena memoria.

Quinto: 22 de nuestros hermanos tuvieron el mismo destino a manos de los godos.

TiTo: (A Quinto) Silencio. (A Tamora) $\mathrm{Ha}$ pasado mucho tiempo hermosa Tamora.

Tamora: Suficiente para olvidar las diferencias del pasado.

TiTo: El pasado no se olvida.

Tamora: Pero se perdona.

TiTo: Tal vez ya nos hemos perdonado.

Tamora: De eso se encarga el tiempo.

TiTo: ¿Ha pasado el tiempo suficiente?

Tamora: Si no há pasado, pasará.

(Pausa)

TiTo: Brindemos por los héroes y cenaremos antes de firmar la reconciliación.

Quinto: Vencímos y abrimos nuestra casa a los derrotados.

Tamora: Aplaudimos la buena voluntad de los vencedores y cenaremos en paz.

Demetrio: Propongo que sigamos el ejemplo de nuestra madre y abandonemos las armas en un sitio donde no alcancemos a hacernos de ellas mientras estamos a la mesa.

(Silencio)

TiTo: ¿Y com qué cortaríamos nuestros alimentos? ${ }^{2}$

4 Tamora traz um pequeno penteado afro. Permanece à porta, abre os braços, dá uma volta sobre seu próprio eixo, se mostra. Tamora: Completamente desprovida de alfanjes, estiletes ou espadas. TiTo: (Sorridente) Vejo uma Tamora desarmada e creio não conhecê-la. Tamora: (Sorridente) Vejo o grande TiTo e o reconheço por ser o mesmo que ordenou a Bassiano esquartejar meu meu filho Alarbo e alimentou com suas entranhas o fogo do sacrifício. TiTo: Que boa memória. Quinto: 22 de nossos irmãos tiveram o mesmo destino nas mãos dos godos. TiTo: (A Quinto) Silêncio. (A Tamora) Já passou muito tempo, formosa Tamora. Tamora: Suficiente para esquecer as diferenças do passado. TiTo: O passado não se esquece. Tamora: Mas se perdoa. TiTo: Talvez já nos tenhamos perdoado. Tamora: Disso se encarrega o tempo. TiTo: Já passou o tempo suficiente? Tamora: Se não passou, passará. (Pausa). TiTo: Brindemos pelos heróis e cearemos antes de firmar a reconciliação. Quinto: Vencemos e abrimos nossa casa aos derrotados. Tamora: Aplaudimos a boa vontade dos vencedores e cearemos em paz. Demetrio: 
A violência está contida em todos os aspectos da cena, mas não há emprego de recursos realistas. Devido à proximidade entre atores e espectadores, cria-se uma espécie de sinergia que deixa o ambiente tenso. Um recurso que merece menção é a sonoplastia dos duelos de espada, travados intencionalmente muito perto do público das primeiras fileiras. Um instrumentista sentado na platéia maneja um instrumento que simula o zumbido das lâminas cortando o ar e o tilintar do choque entre elas. Em cena, os atores simulam a luta utilizando apenas o cabo das espadas. Porém, muitos espectadores se assustam e reagem aos golpes mais próximos com um inesperado movimento de retração do corpo. De outra forma, a violência é metaforizada quando se usam legumes para representar carnes humanas sendo habilmente destroçadas, de acordo com a técnica dos chefes de culinária japonesa. Os atores se mantêm em estado de alerta, como se estivessem sob permanente ameaça física. A um gesto inesperado do outro, respondem corporalmente, colocando as mãos sobre a espada ou verbalmente, com alguma expressão do tipo “¿que pasa?”.

Além dessas cenas construídas com grande imaginação teatral, a palavra é um recurso poderoso na condução do motivo da violência. Tal é o caso da longa cena em que Lavínia, filha de Tito, passa por um interrogatório em que, formalmente, aceitará seu estupro e mutilação. Os dois irmãos Chirón e Demétrio, a mando de Tamora, executam um longo ritual para o que consideram a "purificação" de Lavínia. Eles vão conduzindo "cordialmente" o interrogatório, sem que ela tenha possibilidade de defesa. Se por um lado lhe dão a palavra, por outro ameaçam-na fisicamente. A cena mostra a ameaça física, enquanto verbalmente, a oratória é usada para eles refutarem as réplicas de Lavínia.
A palavra, que em toda a peça é arma para enganos e traições, parece não levar a nenhum entendimento. A comunicação foi rompida e não há como restituir a paz. No entanto, com a cena de violação de Lavínia, a palavra acaba por adquirir papel mais nobre, justamente quando lhe tiram a possibilidade de falar. Os únicos documentos que esse perverso ritual macabro deixa como prova são o diário de Lavínia e sua língua. O diário aparece várias vezes em cena. Em uma delas, Lavínia mostra a impressão de sua eletrocardiografia. Em outra, sua língua é representada por uma pequena fita cassete digital que salta da boca quando Chirón a arranca. Sem língua e sem mãos, o corpo de Lavínia permanece como suporte mudo de uma escritura invisível. Depois de seu estupro até o final do espetáculo, ela tentará representar repetidamente, através da mímica, os gestos e ações de seus agressores, dizendo no final: "esta é toda a verdade, mas ninguém me escuta”. Somente quando Tito lê as palavras escritas no diário da filha é que compreende os fatos. Poderá então dar prosseguimento à vingança final, quando oferecerá a Tamora um banquete em que, sem saber, ela comerá seus próprios filhos.

A maioria das soluções cênicas encontradas está longe de apontar para uma relação mimética entre texto e cena; pelo contrário, cada uma dessas linguagens tem papel extremamente ativo no processo de constante re-significação e simbolização, o que se concretiza quando texto e cena se encontram no palco, criando associações inusitadas entre o que é dito e o que é mostrado.

É inevitável ao assistir ao espetáculo Mosca não pensar na "experiência" brasileira da violência e compará-la à colombiana, país no qual a população convive há décadas com disputas de poder entre guerrilheiros, paramilitares e

Proponho que sigamos o exemplo de nossa mãe e abandonemos as armas em um lugar onde não a alcancemos enquanto estamos à mesa. (Silêncio). TiTo: E com o que cortaríamos nossos alimentos? (Tradução da autora). 
governo. É surpreendente perceber como essa tragédia real é transposta para o teatro como farsa, fazendo com que nos distanciemos do insuportável para enxergar seu lado patético e grotesco. E é mais surpreendente que o Teatro Petra consiga tal efeito com boa dose de humor, ainda que se trate de humor negro e pesado.

\section{Duas peças argentinas}

O espetáculo La Bohemia é resultado do confronto do texto previamente escrito com um processo de montagem que durou quase dois anos entre improvisações e re-escrituras, em que participaram o autor e diretor Sérgio Boris e os atores do grupo La Bohemia, formado em 1998.

Sosa, cego de nascença, e Ramiro, cego há quinze anos, uniram-se como sócios de um sinistro clube que não sabemos se realmente existe ou se é um embuste. Entre outras atividades, o clube oferece curso de braille para não videntes. Certa manhã, Ibañez, cego há uma semana, bate à porta do clube. A partir daí, forma-se uma espécie de triângulo trágico-cômico. Conflitos que envolvem triângulos tendem sempre a apresentar uma dinâmica de ação: duas pessoas se unem para eliminar uma terceira. No caso de La Bohemia isso acontece com peripécias surpreendentes. Sosa vê vantagem em seduzir Ibañez como sócio de um clube reformulado e incrementado com o dinheiro que o último havia juntado. Ramiro, como conseqüência, deverá ser eliminado: além de não ter dinheiro, está adiantando-se nos estudos de braille, e pode ameaçar a posição privilegiada de Sosa como professor e mentor intelectual do clube.

O cenário proposto é realista: um beliche e um corredor ao fundo, uma pequena biblioteca com livros, um aparelho de som e uma porta com vidro por onde passa a luz. Porém, conforme os atores vão se movimentando e se relacio- nando, começamos a entrar num universo de sensações onde imperam convenções estranhas, descompassos entre a fala e a ação. Numa certa altura, percebemos que os personagens são cegos, mas isso deixa de ser importante para explicar suas ações. A constante fricção entre texto e cena vai minando a superfície realista até se abrirem outros sentidos, exaltados pela privação da visão. O movimento de luzes e sombras e os ruídos sonoros que guiam a movimentação hesitante dos atores dão a impressão de um tempo dilatado. A atração e repulsão dos corpos que se relacionam no espaço pelo tato e pela voz abre uma zona em que as ações e reações humanas seguem a lógica dos instintos. Se a peça mostra "exatamente" o comportamento de três cegos dentro de um cenário realista, em outra dimensão ela vai penetrando os medos da alma e os sentidos ilusórios do corpo. Como as outras peças que se referem ao contexto de seus países, mas também o extrapolam, esta parece aludir à crise política e econômica na Argentina, mas estende-se para qualquer situação em que o exercício da sobrevivência pode se transformar em uma forma de existência selvagem e cega.

Romero le toma la mano a Ibañez.

Romero: Estos son sus ojos ahora. Esta es la silla. (Le lleva la mano al lugar que está nombrando.). Ahora tiene diez ojos, no dos, ésta es la cama, ésta es la pared, muy bien, éste es el combinado (Romero pasea la mano de Ibañez por su cuerpo.) y éste soy yo...

Ibañez: ¿Qué hace?

Romero: Acá el ciego se toca.

Ibañez: Acá no hay nadie.

Romero: ¿Qué?

Ibañez: Y... yo no escucho a nadie.

Romero: Bueno, estamos nosotros... está Sosa... Ibañez: Sí, sí, pero ¿vengo yo sólo al club?

Romero: No, no, cómo va a venir usted sólo, sería una locura... ${ }^{5}$

5 Romero pega a mão de Ibañez. Romero: Estes são seus olhos agora. Esta é a cadeira (Leva a mão de Ibañez ao lugar que está nomeando). Agora tem dez olhos, não dois, esta é a cama, esta é a parede, muito 
La forma que se despliega é um questionamento sobre os alicerces em que está assentada a representação teatral, ao mesmo tempo em que investiga a voga de espetacularização da vida privada e a confusão de fronteiras entre a realidade e a ficção. A peça foi escrita e dirigida por Daniel Veronese, em 2003, para o ciclo Biodrama, um projeto de teatro documental que propõe, como pesquisa, transpor histórias reais para o teatro. Porém, Veronese optou por trabalhar a forma confessional a partir de uma história fictícia que trata da dor de um casal que perdeu um filho. Parece-me que Veronese consegue, ao colocar em cena uma situação que pretende fazer passar por real, descobrir as fissuras entre a realidade e o teatro, demonstrando que a representação é a própria "forma que se desprega" da realidade, para podermos enxergar o que está além ou através dela. Quando a própria realidade se torna ficção, texto e cena não se diferenciam. A cena se torna um simulacro da realidade. O texto, simulacro da verdade. Quando texto e cena se juntam para criar teatro, uma transformação mágica flutua no ar.
Um festival internacional nos permite sempre ampliar e aprofundar a visão sobre o que está acontecendo em outros países, contribuindo para situarmos a nossa produção cênica em relação a aspectos formais e temáticos que estão sendo desenvolvidos em outras regiōes. Porém, mais especificamente, ao mostrar espetáculos de países do continente latino-americano, permite que possamos reconhecer traços comuns e distintos. Apesar de distintos, devido em parte às peculiaridades da história de cada país, compartilhamos de vários aspectos comuns derivados da própria posição geográfica e de conjunturas econômicas semelhantes, mais acentuadas no atual contexto de globalização. Creio que o prazer dessa aproximação reside no desejo de reconhecer semelhanças e diferenças, enriquecendo nossa sensibilidade e aprimorando nossa capacidade de escuta. Ao percorrer longos anos na prática desse intercâmbio, o Festival de Londrina acabou por criar os alicerces de um projeto de integração cultural entre países da América Latina.

bem, este é o aparelho de som (Romero passa a mão de Ibañez por seu corpo) e este sou eu... Ibañez: O que você está fazendo? Romero: Aqui o cego se toca. Ibañez: Aqui não há ninguém. Romero: Que? Ibañez: Eu... eu não escuto ninguém. Romero: Bom, estamos nós... está Sosa. Ibañez: Sim, sim, mas? Venho só eu ao clube? Romero: Não, não, como vai vir só você, seria uma loucura... (Tradução da autora). 


\section{Referências bibliográficas}

BLOOM, Harlod. "Tito Andrônico". In: Shakespeare: a invenção do humano. Rio de Janeiro: Objetiva, 2000, p. 113-23.

DUBATTI, Jorge (org.). Nuevo teatro argentino. Buenos Aires: Interzona, 2003.

FERNANDES, Sílvia. "Apontamentos sobre o texto teatral contemporâneo". In: Sala Preta. São Paulo: ECA-USP, 2001, ano 1, no. 1.

GRIFFERO, Ramón. Tus deseos en fragmentos. In: www.griffero.cl

REBOUÇAS, Ana Maria. Poética cênica na dramaturgia brasileira contemporânea. Dissertação de mestrado. São Paulo: ECA-USP, 2001.

RUBIANO, Fábio. Mosca. Texto inédito. 